\title{
STADION SEPAK BOLA MULTIFUNGSI
}

\author{
Randy Yuliant ${ }^{1)}$, Budi Adelar Sukada ${ }^{2)}$ \\ 1) Program Studi S1 Arsitektur, Fakultas Teknik, Universitas Tarumanagara, randy.ry10@gmail.com \\ 2) Program Studi S1 Arsitektur, Fakultas Teknik, Universitas Tarumanagara, budisukada@yahoo.com
}

\begin{abstract}
Abstrak
Gelanggang Olahraga Remaja (GOR) Soemantri Brodjonegoro, salah satu fasilitas olahraga yang berada di wilayah Kuningan, Jakarta Selatan. Proyek ini berbicara mengenai aplikasi dari tujuan mulanya dibangunnya GOR ini. Proyek ini akan terfokus kepada stadion yang merupakan salah satu fasilitas utama dari GOR Soemantri Brodjonegoro dan mengaitkan dengan konsep Architourism yang akan membuat stadion ini bukan hanya untuk penyelenggaran pertandingan sepak bola saja, tetapi bisa menjadi sebuah magnet ataupun daya tarik untuk memikat wisatawan ataupun masyarakat berkunjung ke stadion ini kedepannya. Menjadikan stadion ini sebagai destinasi wisata hiburan lain yang menyehatkan bagi masyarakat di kota Jakarta, terkhusus Jakarta Selatan yang merupakan wilayah padat pusat ekonomi dan bisnis, serta wisatawan asing dengan berbagai tempat hiburan berupa pusat perbelanjaan. Di sisi lain stadion ini juga dapat difungsikan untuk menunjang dan meningkatkan kualitas dari pesepakbolaan Indonesia. Proyek ini akan membahas juga mengenai kondisi sepak bola Indonesia saat ini, permasalahan yang ada, dan hal-hal yang bisa dilakukan stadion ini untuk membantu menyelesaikan masalah yang ada saat ini dalam pesepakbolaan Indonesia.
\end{abstract}

Kata kunci: OR Soemantri Brodjonegoro, Stadion, Sepak Bola, Wisata

\begin{abstract}
Youth Sports Center (YSC) Soemantri Brodjonegoro, one of the sports facilities in the Kuningan area, South Jakarta. This project talks about the application of the purpose of the initial construction of this GOR. This project will focus on the stadium which is one of the main facilities of GOR Soemantri Brodjonegoro and associate it with the Architourism concept that will make this stadium not only for football matches, but can be a magnet or an attraction to attract tourists or the public to visit this stadium going forward. Making this stadium another entertainment destination that is healthy for the people of Jakarta, especially South Jakarta, which is a densely populated economic and business center, as well as foreign tourists with various entertainment venues in the form of shopping centers. On the other side of this stadium can also be used to support and improve the quality of Indonesian footballers. This project will also discuss the current conditions of Indonesian football, the problems that exist, and the things this stadium can do to help solve the problems that currently exist in Indonesian football.
\end{abstract}

Keywords: YSC Soemantri Brodjonegoro, Stadium, Football, Tourism

\section{PENDAHULUAN}

Pemilihan proyek wisata olahraga didasari karena begitu padatnya aktivitas kerja setiap individu yang dihabiskan setiap harinya dari pagi hingga sore. Data menurut survey yang dilakukan Columbia University Medical Centre, rata - rata sekitar 12,3 jam dari 16 jam waktu terjaga sehari masyarakat dihabiskan untuk duduk dan hal tersebut mengakibatkan potensi lebih rentan bagi seseorang mati di usia dini. Sebagian besar orang menyisihkan waktu untuk refreshing bersama teman dan keluarga di hari libur atau di waktu kosongnya, namun tidak jarang aktivitas yang dilakukan jugalah kembali duduk, contohnya seperti menonton bioskop ataupun pertunjukkan hiburan. 
Pemilihan wisata olahraga diharapkan agar setiap individu dapat memiliki kegiatan menyehatkan dalam melakukan refreshing. Olahraga adalah salah satu bentuk usaha memperoleh kehidupan yang lebih sehat. Hal yang memperparah kondisi di Indonesia adalah bahwa 4 dari 5 orang Indonesia malas atau jarang berolahraga menurut survey bertajuk "Gaya Hidup Sehat dan Aktif" yang digagas oleh Perhimpunan Osteporosis Indonesia (Perosi).

Lalu, bentuk olahraga apa yang dibutuhkan dan paling tepat untuk dijadikan suatu wisata dari ruang metropolis yang ada?

Setelah melakukan beberapa pencarian data dan analisa, dapat kita sadari juga bahwa salah satu olahraga yang dianggap termasuk paling murah adalah sepak bola dan sepak bola sendiri juga tidak lekang oleh waktu karena telah dimainkan mulai sekitar tahun 3000 SM. Bukti kuat yang dapat kita temui adalah, baik masyarakat desa maupun kota, masyarakat kalangan bawah maupun atas, anak - anak atau dewasa bermain sepak bola. Tidak jarang kita melihat anak anak bermain sepak bola di jalanan. Fakta yang memperkuat adalah bahwa Indonesia merupakan negara penggemar sepak bola terbesar kedua di dunia dan nomor 1 di Asia Pasifik menurut data dari CNN.

Tentu dengan data di atas, seharusnya Indonesia bisa menjadi salah satu negara dengan kualitas pesepakbolaan yang cukup baik, apalagi Indonesia adalah salah satu negara dengan penduduk yang sangat besar jumlahnya.

\section{METODE}

Metode perancangan yang digunakan adalah penggalian informasi dengan menggunakan literatur buku dan media elektronik, dengan memperhatikan ketentuan-ketentuan atau aturan yang telah tercantum dalam standard Asian Football Confederation (AFC) dan juga Federation Internationale de Football Association (FIFA). Kemudian melakukan survey lapangan ke tapak beserta lingkungan kawasannya, serta melihat dan mempelajari dari beberapa referensi studi kasus.

\section{DISKUSI DAN HASIL}

Proyek ini merupakan proyek REDESAIN dari Stadion Soemantri Brodjonegoro. Kondisi stadion saat ini terbilang cukup memprihatinkan, mengingat bahwa stadion ini bahkan pernah menjadi saksi atas beberapa atlit internasional ternama yang datang berkunjung dan bertanding di stadion ini. Oleh sebab itu, proyek ini akan meredesain stadion menjadi lebih baik dari segi fasilitas. Stadion ini akan mengikuti standar atau aturan yang telah ditentukan oleh FIFA dan penambahan kapasitas penonton.
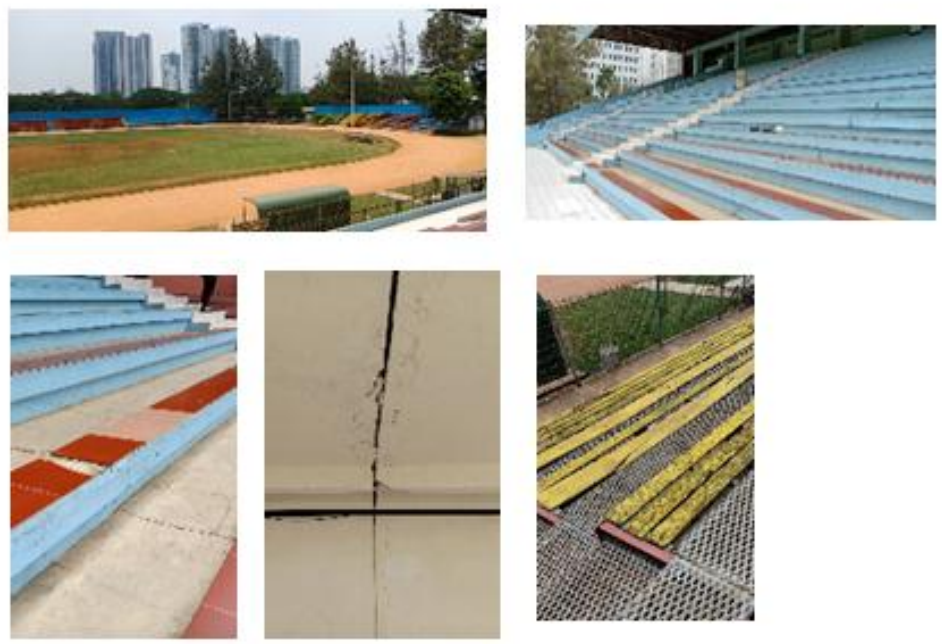

Gambar 1. Kondisi Stadion Saat Ini 
Sejarah awalnya didirikan stadion ini adalah gubernur Ali Sadikin membuat stadion ini untuk mahasiswa dan untuk dikelola juga oleh mahasiswa. Namun dalam prosesnya akhirnya stadion ini tidak bisa dikelola dengan baik oleh mahasiswa, lalu pengelolaan diserahkan kepada Pemda DKI, dan pada akhirnya dikontrak oleh Grup Bakrie mulai tahun 1990-an sampai saat ini. Tujuan awal dibangunnya stadion ini telah ditinggalkan. Proyek ini akan menghidupkan kembali tujuan awal dibangunnya stadion Soemantri karena terkait adanya Universitas Bakrie di kawasan tapak. Mahasiswa Universitas Bakrie lah yang akan ikut mengelola stadion ini. Stadion ini juga digunakan untuk penyelenggaraan pertandingan berlevel mahasiswa dengan tujuan pembinaan dan dapat menemukan bakat muda pesepak bola Indonesia, dengan harapan dapat mendongkrak prestasi sepak bola Indonesia.

Gambar 3. Program yang dihadirkan dalam Stadion

Terdapat 2 program stadion, dimana yang pertama stadion ini memiliki area sejarah mengenai perkembangan sepak bola dan yang kedua terkait ke arah mahasiswa, yaitu area galeri sepak bola liga mahasiswa. Stadion ini juga akan berfokus dalam penyelenggaran pertandingan sepak bola liga mahasiswa.

Stadion ini juga memiliki program dimana terdapat ruang VIP, dimana menonton dengan view terbaik dengan kenyamanan sofa. Nuansa yang dirasa seperti menonton bioskop di studio yang Premier.

Stadion ini dengan program - program yang ada diharapkan dapat menciptakan daya tarik masyarakat untuk berkunjung ke stadion, namun bukan hanya berkunjung untuk menonton pertandingan, tetapi juga untuk datang berkunjung melihat - melihat galeri seputar sejarah sepak bola. Lapangan di stadion ini pun juga akan disewakan bagi masyarakat yang ingin bermain sepak bola, guna untuk memberi masyarakat hiburan sehat di kawasan Jakarta Selatan yang terkenal dengan padat pusat perekonomian, bisnis, wisatawan asing, dan hiburan pusat perbelanjaan. 
Gambar 4. Tampak Muka dan Samping Stadion

Gambar 5. Penggunaan Material Bangunan pada Stadion

\section{KESIMPULAN DAN SARAN}

Stadion ini diredesain selain karena kondisi stadion saat ini yang sudah kurang begitu baik, juga karena ingin menghidupkan kembali fungsi awal dari dibangunnya stadion ini, yakni bagaimana mahasiswa (generasi muda penerus bangsa) dapat mengambil andil (tanggung jawab) untuk memelihara dan mengelola stadion ini. Mahasiswa Universitas Bakrie lah yang bertanggung jawab, berkaitan karena kepemilikan stadion saat ini dikontrak oleh Grup Bakrie sendiri. Stadion ini melalui beberapa program didalamnya, mengedepankan penggunaan stadion lebih terfokus kearah mahasiswa (liga sepak bola mahasiswa) dengan adanya juga galeri terkait perkembangan dari liga sepak bola mahasiswa itu sendiri. Hal ini untuk memperkuat generasi muda pesepak bola di Indonesia agar ke depannya Indonesia bisa berbicara lebih banyak di kancah sepak bola internasional.

Stadion ini juga dibangun untuk sebagai destinasi wisata, terkait konsep Architourism. Dimana stadion ini hadir di tengah-tengah padatnya pusat ekonomi, bisnis, dan wisatawan asing. Di kawasan Kuningan Jakarta Selatan ini juga, terdapat begitu banyak hotel bintang 5 dan berbagai hiburan berupa pusat perbelanjaan.

Stadion ini dihadirkan dengan upaya agar masyarakat bisa memiliki hiburan berupa terkait galeri sepak bola dengan sejarah dan perkembangan sepak bola itu sendiri, dan juga dapat menjadi pusat hiburan sehat. Stadion ini sendiri juga akan dibuka untuk masyarakat umum dapat menyewa agar masyarakat bisa lebih sering melakukan aktivitas olahraga di tengahtengah sibuknya aktivitas yang bisa menurunkan kondisi kesehatan.

Bentuk dari stadion ini juga diharapkan bisa menjadi pusat perhatian masyarakat untuk mengunjungi stadion ini untuk sekedar berfoto dan merasakan nuansa menonton VIP (nuansa menonton sepak bola seperti dalam studio Bioskop Premier) dengan disediakannya juga makanan dan minuman. 


\section{REFERENSI}

Neufert, Ernst. Jilid 2. Data Arsitek. Jakarta : Erlangga.

Specht, Jan. (2014). Architectural Tourism : Building for Urban Travel Destination. Ebook : Springer.

https://resources.fifa.com/mm/document/tournament/competition/51/53/98/safetyregulatio ns_e.pdf diunduh 14 September 2018

https://bola.kompas.com/read/2010/06/10/15121934Indonesia..Penggemar.Bola.Terbanyak.S e-Asia.Pasifik.diunduh 12 Juli 2018

https://bola.inilah.com/read/ detail/1785107/inilah-kekurangan-sepak-bola-indonesia-di-mata -afc diunduh 14 Juli 2018

https://www.ber itasatu.com/kesra/329610-4-dari-5-orang-indonesia-malas-berolahraga.html diakses 12 Juli 2018

https://www.indosport.com/sepakbola/20160313/ gor-soemantri-dikuasai-bakrie-hinggadisinggahi-luis-suarez diakses 20 September 2018 